\title{
The Grandmother Effect and the Uniqueness of the Human Aging Phenotype
}

\author{
James G. Herndon Lary C. Walker \\ Yerkes National Primate Research Center, Emory University, Atlanta, Ga., USA
}

\section{Key Words}

Grandmother hypothesis - Evolution - Cognition • Aging •

Non-human primates

\begin{abstract}
This issue of Gerontology includes a response by van Bodegom et al. to Herndon's recent article on the implications of the grandmother hypothesis for studies of aging and cognition. Although this hypothesis will doubtlessly continue to stimulate discussion, we focus here on our contention that human and non-human primate life histories have evolved essential differences and that these should be addressed in studies comparing aging in humans and chimpanzees.
\end{abstract}

Copyright $\odot 2009$ S. Karger AG, Basel

Early humans are thought to have lived in polygynous groups. Van Bodegom et al. [1] argue that the presence of grandmothers in such a setting would not have provided any advantage to children, citing their own work indicating that the presence of grandmothers is not beneficial to survival in a polygynous society in contemporary Ghana. The argument against an evolutionary benefit of grand- mothering on survival, if correct, would also preclude any co-evolution of cognitive benefits associated with grandmothering. Further, they see no need to explain the 'puzzle' of long post-reproductive survival, which they claim is a recent development in human history.

Herndon [2] noted the controversial nature of the grandmother hypothesis, and the paper by van Bodegom et al. is a thought-provoking argument against it. The debate will surely continue. We do not strive here to refute each of their arguments, but we do take issue with key conclusions of their article that are based on the idea that menopause is 'a recent epiphenomenon of our increased life span'. Indeed, if this were true, there would be no need for an evolutionary explanation of post-reproductive human life, whether it is the grandmother hypothesis or another explanation. Therefore, let us examine the argument that menopause is merely an epiphenomenon.

The fact that median age at death was around 40 years during most of human evolutionary history does not necessarily mean that only a very small proportion of the adult population reached advanced age, because much of the mortality among early humans was likely to have been in infancy. Hawkes [3] notes that in historical and contemporary hunter-gatherer societies with short me-

\section{KARGER}

Fax +4161306 1234

E-Mail karger@karger.ch

www.karger.com (c) 2009 S. Karger AG, Basel

Accessible online at: www.karger.com/ger
James G. Herndon, PhD

Yerkes National Primate Research Center, Emory University

954 Gatewood Rd. NE, Atlanta, GA 30329 (USA)

Tel. +1 404727 7752, Fax +1 4047273278

E-Mail james.herndon@emory.edu 
dian life expectancies, most females who survive childhood live long enough to undergo menopause. An analysis of life tables presented in the same article shows that, even with median life expectancies as low as 20 years, more than half of the adult population can be $>50$ years of age. Peccei [4], the author cited by van Bodegom et al. to support their contention that long life occurred rarely among early humans, actually reaches an opposite conclusion regarding whether menopause is an artifact of modern human longevity. We agree with Peccei's argument that at least some human females have experienced menopause for the past thousands of years, and that there is 'no support for the notion that menopause is the result of recent increases in life expectancy'.

A corollary of the viewpoint that menopause is only an artifact of life span changes is the claim that, without our recent increase in longevity, human life history would be 'very similar to the life history of chimpanzees or rhesus monkeys because most humans would also not live long enough to experience a post-reproductive life span' [1]. Thus, van Bodegom et al. imply that the sharp contrast in life history of the three species, as shown in Herndon's figure 1 [2], is an artifact of the use of modern, rather than historical demographic data. The notable point of figure 1, however, as supported by a growing body of data, is that even under optimal conditions for all three species (and excluding infant mortality for the non-humans), only humans are likely to survive many years past the reproductive phase of life. It seems clear that this sharp difference in life span and in the relationship between life span and reproduction is genetically determined. If reliable data were available on reproduction and longevity of the three species in feral conditions involving increased extrinsic mortality, it is likely that the contrasts among the life history patterns would be even greater, with the non-human species even more rarely experiencing menopause, while at least some humans would do so.

A further argument by van Bodegom et al. is that there has been no evolutionary selection for robustness in old age, and that this is indicated by the prevalence of such age-related diseases as Alzheimer disease, Parkinson disease, cardiovascular disease, and cancer. Two of the diseases they mention, Alzheimer and Parkinson, have not yet been observed in non-human primates. However, it is not uncommon to find cerebral $\beta$-amyloid pathology in chimpanzees in their 40 s and 50s $[5,6]$, ages at which such lesions are virtually absent in humans. (Indeed, $\beta$ amyloid deposits have been noted in orangutans in their 30s [7].) Furthermore, a post-mortem study of a 41-yearold chimpanzee revealed the presence of $\tau$-positive neu- rofibrillary tangles virtually identical to those seen in human Alzheimer disease [6]. The presence of the two cardinal lesions of Alzheimer disease - $\beta$-amyloid plaques and neurofibrillary tangles - in chimpanzees should motivate additional research to determine whether our closest biological relatives might also exhibit other aspects of Alzheimer disease as well.

The other two late-life disorders, cardiovascular disease and cancer, exhibit very different epidemiologic patterns in humans and chimpanzees. Most human heart disease is caused by atherosclerosis, while in chimpanzees it is predominantly caused by myocardial fibrosis [8]. There are also differences with respect to cancer, with humans having higher risk. A recent paper [9] relates differences in malignancy pattern to differences in cognitive capacity. The authors point out that many differences in genes in human and chimpanzee brains are related to reduced apoptotic cell death in humans, a trait that may support our increased cognitive ability. They hypothesize that selection for increased cognitive ability has had the side effect of increased risk for cancer and other diseases associated with reduced apoptotic function. In each of these cases, humans and chimpanzees show different patterns of disease, but the fact that humans fail to show the chimpanzee phenotype, but instead are susceptible to other diseases (such as atherosclerosis and neurodegenerative disorders, which are rare in apes), suggests that humans evolved a robustness that grants them additional useful years beyond menopause, but which ultimately exposes them to a new constellation of disorders toward the end of their extended lives.

In conclusion, we agree that the grandmother hypothesis is not accepted by all researchers, and we look forward to additional evaluation and competing theories of aging. We contend, however, that the human phenotype differs qualitatively from that of non-human primates in several ways, including our uniquely long post-reproductive life span and the complexity of our brain and cognitive function. Given the close biological relationship between humans and chimpanzees, a comparative analysis of the cessation of reproduction and the potential benefits of post-reproductive survival could shed singular light on this intriguing stage in the life history of both species.

\section{Acknowledgements}

Supported by National Institutes of Health grants P51RR000165 and P01AG026423. 


\section{References}

1 Van Bodegom D, Rozing M, May L, Kuningas $\mathrm{M}$, Thomese F, Meij $\mathrm{H}$, Westendorp R: When grandmothers matter. Gerontology 2010 , in press.

2 Herndon J: The grandmother effect: implications for studies on aging and cognition. Gerontology 2010, in press.

3 Hawkes K: Human longevity: the grandmother effect. Nature 2004;428:128-129.

4 Peccei JS: Menopause: Adaptation or epiphenomenon? Evol Anthropol 2001;10:43-57.
5 Gearing M, Rebeck GW, Hyman BT, Tigges J, Mirra SS: Neuropathology and apolipoprotein E profile of aged chimpanzees: implications for Alzheimer disease. Proc Natl Acad Sci USA 1994;91:9382-9386.

- 6 Rosen RF, Farberg AS, Gearing M, Dooyema J, Long PM, Anderson DC, Davis-Turak J, Coppola G, Geschwind DH, Pare JF, Duong TQ, Hopkins WD, Preuss TM, Walker LC: Tauopathy with paired helical filaments in an aged chimpanzee. J Comp Neurol 2008; 509:259-270.

7 Gearing M, Tigges J, Mori H, Mirra SS: $\beta$ Amyloid (A $\beta$ ) deposition in the brains of aged orangutans. Neurobiol Aging 1997;18: 139-146.
8 Varki N, Anderson D, Herndon J, Pham T, Gregg C, Cheriyan M, Murphy J, Strobert E, Fritz J, Else J, Varki A: Heart disease is common in humans and chimpanzees, but is caused by different pathological processes. Evol Appl 2009;2:101-112.

\9 Arora G, Polavarapu N, McDonald JF: Did natural selection for increased cognitive ability in humans lead to an elevated risk of cancer? Med Hypotheses 2009;73:453-456. 